\title{
O CONCEITO DE EXPERIÊNCIA social em François Dubet: Possibilidades analíticas
}

\author{
Rodrigo Manoel Dias da Silva ${ }^{1}$
}

\begin{abstract}
Resumo
Este artigo pretende discutir algumas possibilidades analíticas do conceito de experiência social, desde a abordagem de François Dubet. Apresentaremos uma breve revisão teórica, a partir da qual faremos um duplo movimento interpretativo: constituir a experiência social enquanto ferramenta analítica e investigativa e, ao mesmo tempo, problematizar o possível alcance metodológico do uso deste referencial analítico em pesquisas na área de Ciências Sociais.
\end{abstract}

Palavras-chave: Experiência social. Ator social. Subjetividade.

\section{The Concept of Social eXPerience in François Dubet: ANAYLITICAL POSSIBILITIES}

\begin{abstract}
This article seeks to discuss some analytical possibilities for the concept of social experience, employing the approach formulated by François Dubet. We present a brief theoretical review, based on which we move in two interpretive directions: we constitute social experience as an analytical and investigative tool and, at the
\end{abstract}

\footnotetext{
${ }^{1}$ Doutorando em Ciências Sociais pela Universidade do Vale do Rio dos Sinos (UNISINOS-RS); bolsista Capes.
} 
same time, we problematize the potential methodological scope of the use of this analytical reference in Social Science research.

Keywords: Social experience. Social actor. Subjectivity.

\section{Primeiras Palavras}

$\mathrm{E}$ ste artigo parte de uma pesquisa empírica que analisou o alcance e a efetividade das práticas de participação na escola pública (SILVA, 2008), a fim de discutir as lógicas de ação política que operam nas experiências de participação naquele espaço social. A pesquisa, de orientação etnográfica, teve por base 0 acompanhamento sistemático da participação política em duas escolas públicas localizadas em municípios do interior do Estado do Rio Grande do Sul, assim como dezesseis entrevistas a diversos atores presentes na instituição de ensino: pais, estudantes, docentes e gestores. Optamos, assim, por centrar a análise na participação discente nos mecanismos instituídos e reconhecidos no âmbito institucional, procurando observar como os atores sociais elaboram suas experiências sociais nestes processos.

A pesquisa, recentemente concluída, identificou algumas lógicas de ação que produzem sentidos às práticas de participação política, da mesma forma que posicionou, analiticamente, a noção de experiência social (DUBET, 1994) como categoria central a um estudo antropológico sobre as interfaces entre a política e a escola. Desta forma, os dados coletados foram interpretados a partir da perspectiva teórica da Sociologia da Experiência tendo como ferramentas analíticas as noções de experiência social e de lógicas de ação.

Os dados empíricos coletados revelaram-nos que não podemos compreender as ações dos atores sociais sob um programa único, mas sob combinações de lógicas distintas e incoerentes, o que nos remeteu à idéia de lógicas de ação. No referido estudo, identificamos três lógicas de ação política: participação como expressão da desigualdade dos méritos escolares, participação como estratégia de relação com a instituição e participação como possibilidade de integração à dinâmica escolar.

Interpretamos que as práticas de participação discente na escola revelam uma tendência em integrar os atores na dinâmica escolar decorrentes, em alguma medida, da própria revisão que a instituição escolar tem feito de seus modos de gestão na contemporaneidade. Por esta leitura, ficou-nos evidente que a escola precisa da participação estudantil, enquanto elemento de adesão, para gerir seus 
tempos e espaços de participação política. 0 que, sutilmente, revelou-nos uma inversão no quadro de expectativas depositadas em torno da participação política, pois se, antes, 0 ator precisava participar para garantir seus direitos de cidadania (KRISCHKE, 2004), hoje, a instituição precisa da participação do ator. Há, nesta inversão, algumas pistas para pensarmos essas lógicas de ação: os modos de gestão da escola dependem da integração participativa (voluntária, mas não autônoma) dos atores presentes na instituição escolar.

Este artigo, particularmente, interessa-se em discutir o potencial analítico do conceito de experiência social, desde a abordagem de François Dubet, de maneira que possamos apresentar uma breve revisão teórica sob a qual constituímos a experiência social enquanto ferramenta analítica e investigativa e, ao mesmo tempo, problematizarmos o possível alcance metodológico do uso deste referencial analítico. Para tal finalidade, segmentamos o presente artigo em quatro seções textuais. Na primeira seção, apresentaremos alguns antecedentes das relações entre sociedade e indivíduo, as quais, pelo menos desde Simmel, parecem sinalizar à relevância das experiências dos atores sociais enquanto categoria sociológica. Na segunda seção, deslocaremos a leitura às imbricações entre experiência social, sociedade e Estado enquanto elementos constituintes da política, tal como comentado por Dubet. Na terceira, abordaremos a contribuiç̧̃̃o de Alain Touraine em sua abordagem à ação social, a qual nos parece aproximarse à noção de experiência, desdobrando-se enquanto potencial analítico acerca das relações políticas na atualidade. Na última, objetivamos sistematizar as potencialidades da análise sociológica que se desdobram desde a Sociologia da Experiência na contemporaneidade.

\section{SiMMEL, OS CÍRCULOS SOCIAIS E A AÇÃO}

A noção de ação em Ciências Sociais acabou por receber inúmeras teorizações, uma vez que distintas matizes teóricas têm revelado seu potencial heurístico e mesmo metodológico, desde os Clássicos até expressões sociológicas mais recentes. A origem desta tematização, em suas perspectivas clássicas, reside nas primeiras elaborações sociológicas alemãs, principalmente aquelas realizadas por Georg Simmel e Max Weber. Nesta seção textual, daremos relevo à contribuição de Simmel, uma vez que sua noção de 'ações sociais' oportuniza-nos compreender alguns desdobramentos deste conceito em expressões sociológicas atuais. Cabe destacarmos que a leitura de Simmel, tal como realizamos, aponta 
para uma perspectiva de abordagem metodológica que evidencia as interações sociais como elemento de compreensão do social, em detrimento daqueles que observam os elementos estruturantes da sociedade. A opção por esta leitura decorre de sua maneira de perceber as abstrações e ordenamentos da vida social, identificando a sociedade como aquelas circunstâncias em que vários indivíduos entram reciprocamente em ação.

Assim, as análises do conceito de sociedade deveriam basear-se na distinção entre suas formas e conteúdos, designando a sociedade, provavelmente, como uma metáfora. Nas palavras do autor:

Este punto de vista surge mediante un análisis del concepto de sociedad, que se caracteriza por la distinción entre forma y contenido de la sociedad - teniendo presente que esto en realidad no es más que una metáfora para designar aproximadamente la oposición de los elementos que se desea separar; esta oposición habrá de entenderse en su sentido peculiar, sin dejarse llevar por la significación que tienen en otros aspectos tales designaciones provisionales (SIMMEL, 1986, p. 15).

Esta abordagem revela que aquilo que conhecemos como sociedade é o resultado de sínteses de ações sociais recíprocas, ou mesmo que a sociedade é constituída por distintas formas de ação recíproca. Para o autor, neste sentido, não poderíamos considerar a existência de uma sociedade em sua forma universal, mas a considerarmos como um conjunto de ações sociais entre indivíduos que interagem reciprocamente. Aproxima-se deste debate a própria noção de socialização, pois o uso conceitual que faz o autor - ações sociais recíprocas (idem, p. 16) - se distingue de outras abordagens que entendem a socialização como a integração do indivíduo a uma sociedade que estaria previamente determinada como em Durkheim, por exemplo. A impossibilidade de generalizar a sociedade refere-se aos distintos graus de socialização presentes nos grupos sociais, uma vez que estas relações podem possuir formas e conteúdos diversos, intermediando fluxos de relações entre os atores envolvidos nestes processos.

Assim, o que faz a 'sociedade' são suas ações recíprocas. Pois:

[...] lo que hace que la 'sociedad', en cualquiera de los sentidos de la palabra, sea sociedad, son evidentemente las diversas clases de acción recíproca a que hemos aludido. Un grupo de hombres no forma sociedad porque exista en cada uno de ellos por separado un contenido vital objetivamente determinado o que le mueva individualmente (SIMMEL, 1986, p. 17).

Estas relações entre formas e conteúdos das relações sociais são 
constituintes não só de uma noção variável de sociedade, como podem indicarnos a dedução de que não há uma sociedade absoluta, uma vez que não há uma ação absoluta. Metodologicamente, Simmel prossegue a reflexão indagando como "ser possível a sociedade?" (idem, p. 41), questão esta que remete às condições discursivas que elaboram uma noção de sociedade desde as interações entre os indivíduos. Ao operar sociologicamente com as ações sociais recíprocas, o autor identifica algumas condições para a socialização. Uma destas que, a nosso ver, merece destaque é o princípio relacional que organiza as ações sociais recíprocas, pois cada indivíduo é determinante daquilo que ocorre interna e externamente nestas relações. As sociabilidades determinam-se neste jogo de identificações entre o indivíduo e o social. Compreendemos por sociabilidade "a forma lúdica de sociação", tal como definida pelo autor alemão (SIMMEL, 2006).

A sociabilidade constrói-se nas interações sociais entre os indivíduos nos círculos sociais, desta maneira provoca combinações diversas entre os indivíduos em interação, como já mencionado acima. Desde formas e conteúdos distintos são produzidos efeitos que modificam as próprias relações sociais. Essas combinações, em termos contemporâneos, fazem-nos refletir que, além das redefinições das relações sociais, as interações fazem com que os atores sociais redefinam suas experiências sociais a partir da incongruência de suas lógicas de ação.

Esta observação provoca-nos pensar que as experiências sociais dos indivíduos, assim como as relações em que estes se empenham, são definidas pelos círculos interacionais que constituem - o que atualiza a contribuição de Simmel como um precursor das análises da ação social. Ao mesmo tempo, quando deslocamos os sentidos da ação social à experiência, como produto de interações sociais, acabamos por atribuir-lhe um sentido político, o qual ficará explícito na seção textual seguinte.

\section{SOBRE O CONCEITO DE SOCIEDADE}

Seguindo a linha reflexiva da seção textual anterior, poderíamos supor, portanto, que Simmel antecipa toda uma discussão contemporânea sobre as interações sociais enquanto unidade sociológica de análise. Diante desta percepção, consideramos que semelhantes movimentações analíticas poderiam ser desdobradas quando intencionamos compreender os sentidos da expressão 'sociedade'. Se em Simmel, encontramos os círculos sociais como princípio fundante das relações sociais, por outro lado, inúmeras teorizações subseqüentes 
a definem de modos diferenciados ou até antagônicos. Objetivamos agora, minimamente, delinear alguns destes modos de definição da sociedade, em suas distinções teóricas, interessados em observar como esta noção foi sendo construída em termos sociológicos.

Para elaborarmos um itinerário diante desta finalidade, partimos do reconhecimento de que as relações políticas são definidoras da conceituação, ou definição, da sociedade em termos científicos. Além disso, as imbricações conceituais deste termo poderão, a posteriori, facilitar nossa compreensão das mutações analíticas que darão condições de possibilidade à produção e uso do conceito de experiência social. Por enquanto, seguiremos o delineamento realizado Dubet (1994), fazendo uso dos comentários realizados por este autor e agregando outras contribuições específicas.

Segundo Dubet (1994), as noções sociológicas de indivíduo e de sociedade são bastante complexas, ambíguas e polissêmicas, uma vez que poucos foram aqueles que se aventuraram a defini-las. A definição de sociedade parece adquirir maior exatidão quando adjetivada: sociedade de massa, sociedade primitiva, sociedade industrial, sociedade moderna, sociedade pós-industrial, sociedade pós-moderna. A sociologia clássica, em suas diversas tradições, parece traçar algumas características desta "sociedade", e a revisão desses traços, embora não possibilite encontrar uma essência de sociedade, nos permite buscarmos alguns delineamentos teóricos que nos auxiliem a construir um referencial analítico acerca destas relações políticas entre ator social e sociedade.

Dentro deste quadro de caracterizações da noção de sociedade, seguiremos a orientação do estudo realizado pelo mesmo sociólogo francês (DUBET, 1994), qual seja: a sociedade é identificada com a modernidade, a sociedade é um Estado Nacional, a sociedade é um sistema e a sociedade é um conflito regulado. Estas categorias são depreendidas de perspectivas sociológicas diferentes, como mostraremos na sequiência.

Então, se a sociedade é identificada com a modernidade, esse primeiro aspecto visível parece dirigir-se à oposição entre sociedade e comunidade, tal como narrada por Tönnies (1973). Esta oposição clássica na sociologia, e tipicamente moderna, apresenta distinções de formato evolutivo entre as duas noções: sendo a sociedade (DUBET, 1994, p. 42) mais complexa, racional, dispõe de alto grau de divisão do trabalho, interessa-se por relações contratuais (formalizadas), compreendendo os espaços profanos, em oposição à comunidade, que: "[...] é 
caracterizada pela simplicidade, pela fraca divisão do trabalho, por um pensamento não-científico, "mágico", por uma extensão limitada, por relações cara a cara, por ordens e castas, por uma dominação do sagrado" (DUBET, 1994, p. 42).

A perspectiva de Tönnies, recuperada desde a sociologia clássica, vincula-se a certo evolucionismo referente ao aparecimento das sociedades e, por extensão, sociedades modernas. Cabe, pois, ao cientista social a hierarquização dessas sociedades segundo seus graus de modernidade. Assim: "A sociedade é identificada com a maneira moderna de se estar em conjunto, a que produz precisamente indivíduos arrancando-os ao feitiço ou à obscuridade - conforme o caso - dos mundos comunitários" (DUBET, 1994, p. 43).

Neste sentido, definir a sociedade consiste em definir os estágios de desenvolvimento em que esta se encontra - sua complexidade - e mesmo de sua racionalização. Mais especificamente, quanto mais moderna é uma sociedade mais garantidas estão as normas e ordens políticas, uma vez que sua formalização passa a ser mais intensa. Ou, nas palavras do próprio Tönnies:

A sociedade, portanto, pela convenção e pelo direito de um agregado, é compreendida como uma soma de indivíduos naturais e artificiais, cujas vontades e domínios se encontram em associações numerosas, mas que permanecem, entretanto, independentes uns dos outros e sem ação interior recíproca (TÖNNIES, 1973, p. 113).

Sob um prisma aproximado, no âmbito da sociologia clássica, a sociedade é identificada com a modernidade. Talvez, possamos também concordar com a tese de que a sociedade é um Estado nacional. Inclusive, parece-nos que a sociedade moderna somente se realiza na forma de um Estado nacional (DUBET, 1994). As afirmativas que identificam a noção de sociedade ao Estado também emergem nas leituras de Florenzano (2007), de Duguit (s/d) ou de Bobbio (1987), possibilitando que possamos notar nestas perspectivas divergentes teoricamente suas ênfases nas imbricações de origem, de elementos constituintes e de poder entre estas categorias. Esta vinculação entre o Estado-Nação e a sociedade tende a ser vista como um quadro político típico das sociedades modernas, porque estas garantem a integração de uma cultura, de uma economia e de um sistema político em torno da soberania nacional.

A soberania é um dos elementos do Estado (DUGUIT, s/d, p. 63). Este princípio de soberania é concebido, desde uma leitura específica, por três características que revelam perspectivas distintas da noção de poder: poder de 
querer, poder de mandar e poder de mandar independente. 0 poder soberano expresso aponta a vontade, a vontade da Nação e, por assim dizer, as determinações do que seja direito subjetivo. Estes aspectos citados revelam o conceito de nação como uma forma de associação moderna, de tal modo que emerge como uma instituição regida por princípios formais.

Ao identificar o Estado como um traço da sociedade, assim como suas continuidades e descontinuidades, Dubet proporciona em sua análise a possibilidade de repararmos na relação entre sociedade e Estado como algo socialmente construído. As relações institucionais podem nos sinalizar aspectos importantes desta trama:

0 Estado nacional é a sociedade dos indivíduos em virtude do papel desempenhado pelas instituições. Mas, da mesma maneira que a noção de sociedade é dupla, ao mesmo tempo sistema de papéis e de valores e realidade 'concreta' do Estado-Nação, a noção de instituição possui também uma dupla significação. Por um lado, as instituições garantem a integração dos indivíduos no Estado-Nação, elas socializam os atores. Por outro lado, as instituições designam os sistemas políticos modernos, distintos dos Estados patrimoniais tradicionais, capazes de representar interesses distintos e de arbitrar entre si (DUBET, 1994, p. 45).

Esta proposição analítica potencializa o entendimento de que as instituições políticas podem ser mais ou menos representativas, assim como seus teores de autonomia podem ser diversificados, pois interesses de grupos distintos podem desenvolver uma (re) definição entre o Estado e a sociedade.

Embora pareçam suficientes as definições de que a sociedade estaria identificada com a modernidade (em suas ênfases na razão e no progresso) e, não obstante, identificada com os tensionamentos à formação do Estado, a identificação da sociedade a um sistema parece representativa de uma tradição sociológica. A afirmativa de que a sociedade é um sistema remete a um campo de estudos que tem em Talcott Parsons uma referência. Segundo este autor:

Pode-se definir a sociedade como o complexo total das relações humanas enquanto se originam da ação em termos de relação meios-fins, intrínseca ou simbólica. Segundo esta definição, a sociedade é apenas um elemento no todo concreto da vida social humana, que também é afetada pelos fatores hereditariedade e ambiente, bem como pelos elementos da cultura (PARSONS, 1973, p. 284). 
Esta tradição sociológica intenciona olhar a sociedade em sua totalidade (um "complexo total", nos dizeres de Parsons) e decorre desta característica 0 fato de afirmar-se que esta tradição é holista, ou seja, afirma que a sociedade é uma unidade funcional. Esta linhagem em sociologia, herdeira de Durkheim, foi largamente difundida pelo pensamento social, de maneira que sua perspectiva funcionalista, de Malinowski a Merton, em suas visões mais abertas ou mais restritas, dominou a representação de sociedade. Esta visão elaborou um argumento sociológico que preponderou ainda até poucos anos atrás: "A sociedade moderna possui uma unidade funcional complexa que permite a análise em termos de sistemas nos quais cada elemento só tem utilidade pela combinação que o liga ao sistema geral da sociedade" (DUBET, 1994, p. 47).

Esta elaboração teórica da sociedade aproxima-se das leituras históricas de um Estado nacional, uma vez que ambas as premissas pressupõem a integração dos indivíduos a uma instituição, a um mercado ou a uma cultura. A última caracterização elaborada pelo sociólogo francês diz respeito à associação da sociedade a um conflito regulado. A sociedade seria para esta vertente, segundo Dubet, um conjunto estratificado, dividido em classes sociais, baseado em trocas desiguais de recursos e contribuições, de maneira que quanto mais se efetiva a retórica da igualdade, mais segmentadas são as relações entre os indivíduos.

A noção de conflito é tratada diferentemente pelos clássicos da sociologia. Desde este olhar, o conflito cumpre o papel de adaptação e integração dos atores em conflito dos atores nele envolvidos, o que reforçaria suas normas e consolidaria suas distinções. A caracterização da sociedade como um conflito regulado pretende afirmar que:

Não há dúvida de que esta representação da sociedade pela sociologia clássica não é revolucionária, mas não é tão conservadora quanto se tem pretendido dizer muitas vezes, sobretudo porque ela reconhece a oposição das classes na sociedade industrial, e porque crê na sua institucionalização num processo que aumenta a integração da sociedade (DUBET, 1994, p. 49).

Utilizamos as caracterizações de François Dubet como matriz para nossas referências analíticas das relações entre Estado esociedade, visando expor o potencial heurístico, presente nestas definições, uma vez que o autor não objetivou a captura de uma essência da sociedade ou do Estado, mas sim recuperar a contribuição de distintas correntes sociológicas que se interessaram por esta temática. Assim, a discussão da sociedade como identificada à Modernidade, ao Estado nacional, a um sistema ou a um conflito regulado elabora um quadro oportuno de definições 
de sociedade, mas, sobretudo, possibilita-nos ver as relações sociais que elaboram/ produzem a própria sociedade. Concordamos com Lopes (2006) quando o autor complementa esta perspectiva de Dubet, inserindo uma categoria antropológica ao enredo aqui descrito, qual seja: que tanto a industrialização, quanto a modernidade ou a formação do Estado-Nação se reproduzem institucionalmente.

Se, então, na primeira seção deste artigo nos pareceu que Simmel antecipa uma discussão contemporânea sobre a constituição da sociedade enquanto modos de sociação, aqui, oportunamente, deslocamos este debate à produção política da sociedade, desde suas definições sociológicas. Sendo assim, a definição da sociedade desde perspectivas divergentes sociologicamente, sem essencializá-la, oportunizou a Dubet a construção da noção de experiência social, pois assim como a sociedade é produzida por entendimentos distintos e incongruentes, a experiência social se faz desde lógicas de ação heterogêneas. Assim, a ação social passa a ser interpretada na ausência de um sentido unitário, sob registros e significações múltiplos. A mesma perspectiva parece encontrar ressonância na obra recente de Alain Touraine, o qual influenciou toda uma escola francesa de Sociologia, inclusive Dubet.

\section{O ATOR SOCIAL E A AÇÃO: NOTAS SOBRE A OBRA ReCEnTE de Alain Touraine}

Em Alain Touraine, encontramos a possibilidade de um ator social atuante e construtor de si mesmo nos campos da cultura, entendida aqui como as experiências sociais (DUBET, 1994) do sujeito em seus encontros com outros atores.

0 ator social em Alain Touraine (1998) é um sujeito que não se realiza individualmente, mas nas relações que se desenvolvem com outros indivíduos, é aquele que expressa vontade de agir e ser reconhecido como ator, constituindo-se no envolvimento em processos sociais. Tal existência é situada em uma rede de conflitualidades que medeia as relações deste indivíduo com os outros e consigo mesmo, rompendo com princípios racionalistas modernos e inserindo-o na esfera cultural.

Semelhante princípio é narrado pelo autor em outra ocasião (TOURAINE, 2006) quando menciona que a decomposição das instituições sociais modernas 
fez triunfar o indivíduo ${ }^{2}$, dessocializado, porém capaz de combater a ordem social dominante. Um ator social constituído por conflitos pessoais, étnicos, geracionais, de gênero, os quais, por imagens distintas, ilustram lutas cotidianas e culturais pontuadas por relações de poder. De tal maneira:

0 sujeito se forma na vontade de escapar às forças, às regras, aos poderes que nos impedem de sermos nós mesmos, que procuram reduzir-nos ao estado de componente de seu sistema e de seu controle sobre a atividade, as intenções e as interações de todos. Estas lutas contra 0 que nos rouba o sentido de nossa existência são sempre lutas desiguais contra um poder, contra uma ordem. Não há sujeito senão rebelde, dividido entre a raiva e a esperança (TOURAINE, 2006, p. 119).

Isso desvela, por esta abordagem, a idéia de que o conflito social em Touraine pressupõe relações desiguais entre atores, ao mesmo tempo em que desvela a idéia de que tais relações são relações de poder. As interações são instáveis. Os conflitos sociais são negociados (DUBET, 1994). Assim, o campo social já não tem unidade central, se faz objetivamente nos confrontos entre o poder e o sujeito, entre a imposição de uma ordem, de uma hierarquia ou de um discurso e os mecanismos de contestação dos sujeitos (TOURAINE, KHOSROKHAVAR, 2001).

\section{EXPERIÊNCIA SOCIAL: EM BUSCA DE UMA DEFINIÇÃO}

Segundo Dubet, está em movimento uma perda do sistema de referências proporcionadas pela sociedade industrial e de constituição de um sujeito autoreferencial, neste sentido, isso representa um declínio de uma idéia de sociedade ou mesmo da morte do social (DUBET; MARTUCELLI, 1996). Segundo essa inferência, as instituições estão perdendo em si mesmas a capacidade de definir subjetividades e, no mesmo movimento, estamos assistindo à derrocada de uma sociedade que integrava seus indivíduos mediante um processo de supersocialização dos agentes através de várias agências de socialização, dentre estas, a família, a escola ou a igreja, em detrimento da efetiva sociedade de indivíduos "subsocializados e anômicos" que dali se originava (TIRAMONTI, 2005).

Neste sentido, evidencia-se que o indivíduo não esteja inteiramente socializado, pois sua ação não se vincula a um programa único e, em Dubet, reparamos que existe algo de inconcluso e opaco na experiência social do

\footnotetext{
${ }^{2}$ Entendemos que, sociologicamente, indivíduo, sujeito e ator são conceitos distintos. Entretanto, tal distinção não se constituiu como objetivo para este estudo.
} 
indivíduo. Pois:

Não existe uma socialização total, mas se processa uma espécie de separação entre a subjetividade do indivíduo e a objetividade de seu papel. E essa socialização não é total, não porque o indivíduo escape do social, mas porque sua experiência se inscreve em registros múltiplos não congruentes (SETTON, 2005, p. 343).

A citação acima traz à reflexão a noção de experiência social elaborada pelo sociólogo francês François Dubet. Tal conceito advém, por um lado, do reconhecimento do contexto de mudanças socioculturais na sociedade européia pós-1990 e, por outro, da experiência empírica e teórica do autor. Mas o que podemos entender por experiência social? É uma noção que designa as condutas individuais e coletivas dominadas pela heterogeneidade dos seus princípios constitutivos e pela atividade dos indivíduos que devem construir o sentido das suas práticas no bojo desta heterogeneidade (DUBET, 1994).

Quando interpretamos as práticas sociais a partir das experiências dos indivíduos, fazemos a análise tendo suas próprias ações como perspectivas de compreensão do social. Assim, a ação do ator passa a ser uma categoria relevante, segundo Touraine (1984, p. 96):

E a acção não é só decisão: é desígnio de orientações culturais, através das relações sociais conflituais. 0 conflito não é nem contradição nem revolta, mas forma social da historicidade, da produção da sociedade por si mesma. Pouco a pouco, para lá do evolucionismo, forma-se a análise de sociedades que por um longo período de crescimentos e de crises, de ameaças atómicas, de totalitarismos e de revoluções, convenceu que deveriam descobrir-se como produto de sua acção e não como a manifestação de uma natureza humana, de um sentido da história ou de uma contradição original.

Esse autor provoca-nos a pensar a sociedade como algo construído nas práticas dos atores, atualizando algumas das premissas já mencionadas por Simmel no início dos anos de 1900. Neste sentido, a ação (interação) seria orientada por princípios culturais, construída nas próprias dinâmicas das relações sociais e elaborada sob certas circunstâncias históricas, de maneira que se colocam em suspenso aquelas explicações aprioristas da vida social. Se a compreensão da sociedade focalizou-se em fatores socialmente construídos, poderíamos inferir que a elaboração da própria sociedade se dá na construção das experiências sociais dos atores (DUBET, 1994).

Quando a questão é colocada em termos de experiência social, assim como 
argumentamos, entendemos que o ator não está totalmente socializado, isto é, a noção de experiência só faz sentido se a ação não for redutível à subjetivação do sistema. 0 ator não é o social internalizado, como reiteram algumas perspectivas sociológicas, porque sua ação não é redutível a um programa único.

\section{Considerações Finais}

0 conceito de experiência social, elaborado por François Dubet, em sua Sociologia da Experiência, orientou sociologicamente estudo que recentemente concluímos em Ciências Sociais (SILVA, 2008). Esta categoria adquiriu centralidade em nosso fazer investigativo quando passamos a observar que a participação política na escola não estava regida por uma lógica única, mas que a participação naquele espaço social era constituída por lógicas de ação advindas das experiências sociais dos atores sociais ali presentes. Neste sentido, compreendemos que o conceito de experiência social traz consigo um conjunto de possibilidades analíticas, de maneira que não somente elabora um escopo teórico como encaminha a um produtivo olhar metodológico.

0 potencial analítico do conceito de experiência social, a partir de nossa ação investigativa, desdobra-se em uma dupla movimentação analítica. A primeira movimentação nos dá condições de possibilidade para que entendamos essas interações sociais como produtoras das práticas de democracia, autonomia e participação. Essas práticas não dispõem, portanto, de definições substancializadas, definidas a priori das práticas sociais, diríamos que elas mesmas são definidas nas práticas sociais - princípio este ressignificado a partir de leituras de Simmel.

$\mathrm{Na}$ segunda movimentação, interpretamos que os processos políticos na contemporaneidade elaboram-se, sejam eles participativos ou não, nas interações sociais, sobretudo quando admitimos que são construídos desde a experiência social destes atores (DUBET, 1994). E a experiência social, analiticamente, traz novas temáticas ao debate, uma vez que interroga sociologicamente os modos de gestão política desde seus princípios: as lógicas de ação, os sentidos da justiça, a dinâmica igualdade-desigualdade, a educação política e a autonomia dos atores em processos participativos (SILVA, 2008). 


\section{REFERÊNCIAS}

B0BBI0, Norberto. Estado, governo, sociedade: por uma teoria geral da política. Rio de Janeiro: Paz e Terra, 1987.

DUBET, François. Sociologia da Experiência. Lisboa: Instituto Piaget, 1994.

DUBET, François \& MARTUCELLI, D. En la escuela: sociología de la experiencia escolar. Buenos Aires: Losada, 1996.

DUGUIT, Léon. Os elementos do Estado. $2^{\text {a }}$ ed. Lisboa: Editorial Inquérito, s/d. DURKHEIM, Emile. Educação e Sociologia. $11^{a}$ ed. São Paulo: Melhoramentos, 1978.

FLORENZANO, Modesto. Sobre as origens e o desenvolvimento do estado moderno no ocidente. Lua Nova, Vol. 71, 2007, p. 11-39.

GAIGER, Luiz Inácio Germany. Por uma Sociologia Dialógica. Estudos Leopoldenses. Série Ciências Humanas, Vol. 35, nº 155, 1999. p. 21-37.

GOFFMAN, Erving. Manicômios, Prisões e Conventos. $4^{\mathrm{a}}$ ed. São Paulo: Perspectiva, 1992.

. A Representação do Eu na Vida Cotidiana. $8^{a}$ ed. Petrópolis: Vozes, 1999 .

HALL, Stuart. A identidade cultural na pós-modernidade. $10^{\mathrm{a}}$ ed. Rio de Janeiro, DP \& A, 2005.

KANT, Immanuel. Pedagogia. Madrid: Akal, 1983.

LOPES, José Rogério. Exclusão Social, Privações e Vulnerabilidade: uma análise dos novos condicionantes sociais. São Paulo em perspectiva, $n^{0}$ 1, Vol. 20, 2006, p. $123-135$

LUZ, Madel T. 0 interacionismo simbólico: breve exposição de uma corrente acionalista em ciências sociais. In: CARVALHO, Maria do Carmo Brant. (org.) Teorias da Ação em Debate. São Paulo: Cortez/PUC, 1993.

MANNHEIM, Karl. A Crise da Sociedade Contemporânea. In: PEREIRA, Luiz \& FORACCHI, Marialice (orgs.). Educação e Sociedade: leituras de sociologia da educação. 6a ed. São Paulo: Companhia Editora Nacional, 1971. p. 321-342

. Educação e Planejamento. In: FORACCHI, Marialice. (org.) Karl Mannheim - Sociologia. São Paulo: Ática, 1982. p. 152-200. 
MARX, Karl. Manuscritos Econômico-Filosóficos. São Paulo: Martin Claret, 2001. MELUCCI, Alberto. A Invenção do Presente: movimentos sociais nas sociedades complexas. Petrópolis: Vozes, 2001.

NETTO, João Paulo. Nótula à teoria da ação comunicativa de Habermas. In: CARVALHO, Maria do Carmo Brant. (org.) Teorias da Ação em Debate. São Paulo: Cortez, 1993. p. 51-64

PARSONS, Talcott. A emergência do conceito de sociedade como categoria sociológica. In: FERNANDES, Florestan (org.). Comunidade e Sociedade. São Paulo: Nacional/Edusp, 1973. p. 269-285

SETTON, Maria da Graça Jacintho. A particularidade do processo de socialização contemporâneo. Tempo Social - Revista de Sociologia da USP. n 2, Vol. 17, 2005. p. 335-350.

SILVA, Rodrigo Manuel Dias da. Experiências sociais e lógicas de ação política: etnografia da participação estudantil na escola pública. Dissertação de Mestrado apresentada ao Programa de Pós-Graduação em Ciências Sociais. Universidade do Vale do Rio dos Sinos, 2008.

SIMMEL, Georg. Sociabilidade - Um exemplo de Sociologia Pura ou Formal. In: MORAES FILHO, Evaristo de. (org.) Georg Simmel: Sociologia. São Paulo: Ática, 1983. p. 165-181

Sociología - Estudios sobre las formas de socialización. Madrid: Alianza, 1986.

Questões Fundamentais da Sociologia. Rio de Janeiro: Zahar, 2006.

TIRAMONTI, Guillermina. La escuela en la encrucijada del cambio epocal. Educação e Sociedade, Campinas, no 92, Vol. 26, 2005 p. 889-890

TÖNNIES, Ferdinand. Comunidade e sociedade como entidades típico-ideais. In: FERNANDES, Florestan. Comunidade e Sociedade. São Paulo: Nacional/Edusp, 1973. p. $96-116$

TOURAINE, Alain. Um novo paradigma para compreender o mundo de boje. São Paulo: Vozes, 2006.

1984.

O Retorno do Actor - Ensaio de Sociologia. Lisboa: Instituto Piaget, . Poderemos viver juntos? Iguais e diferentes. Petrópolis: Vozes, 1998. 
TOURAINE, Alain.; KHOSROKHAVAR, F. A procura de si - Diálogo sobre o sujeito. Lisboa: Instituto Piaget, 2001.

VAN VELSEN, Jaap. A análise situacional e o método de estudo de caso detalhado. In: FELDMAN-BIANCO, Bela. (org.) A Antropologia das sociedades contemporâneas. São Paulo: Global, 1987.

WEBER, Max. A Ética Protestante e o Espírito do Capitalismo. São Paulo: Martin Claret, 2002. 